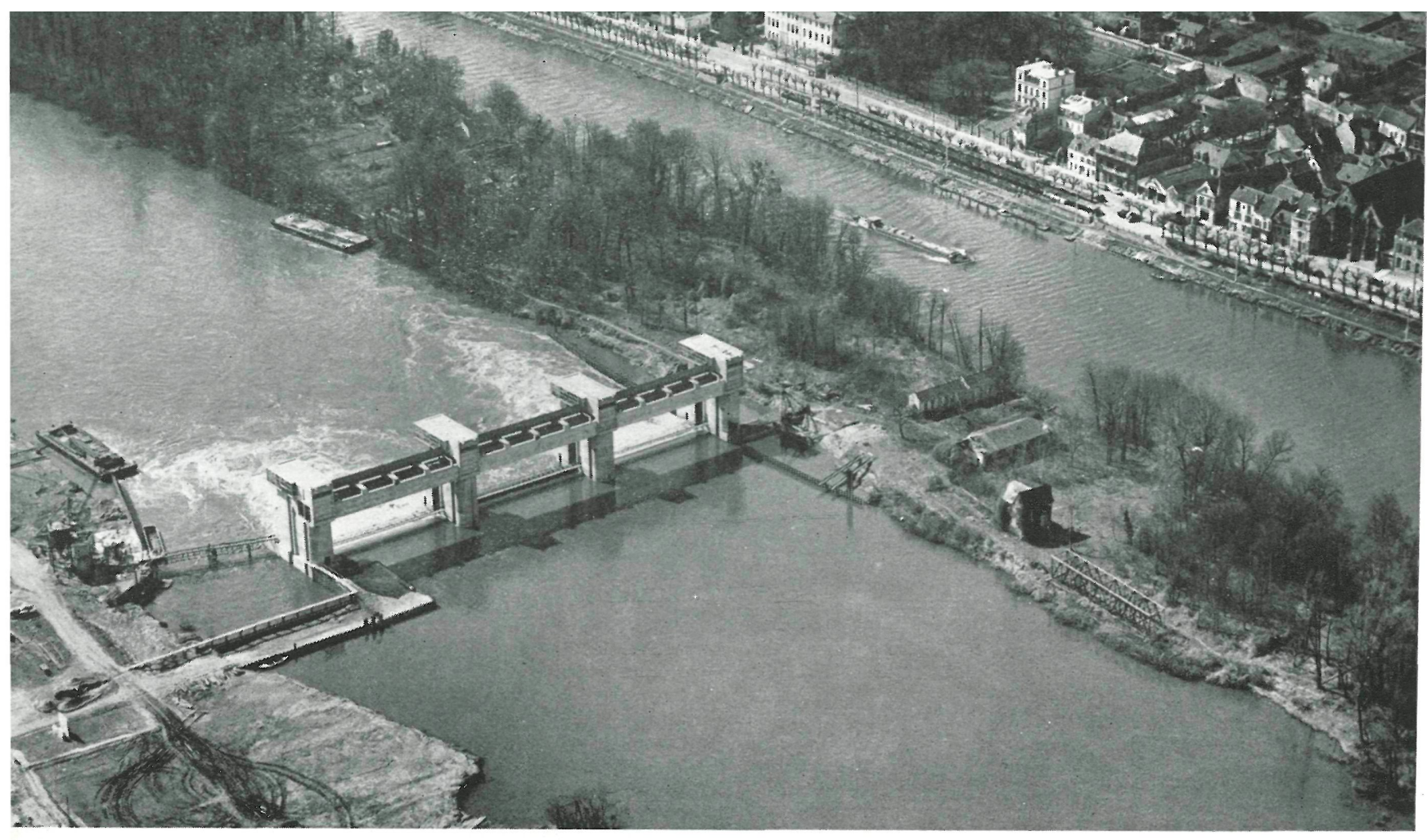

$531 \cdot 54$

\title{
presa Andresy
}

\section{GEORGES VIÉ, ingeniero}

Esta obra, cuya construcción original se remonta al año 1848, se halla situada en las proximidades de la confluencia del río Oise con el Sena, y dentro del término municipal de Andresy (Francia).

La presa actual se apoya sobre una solera de hormigón armado, de 20,5 m de extensión en el sentido del eje del río y de $2 \mathrm{~m}$ de espesor. Debajo de la solera se han hincado varias series de pilotes de hormigón armado con objeto de aumentar la capacidad de sustentación del fondo del río.

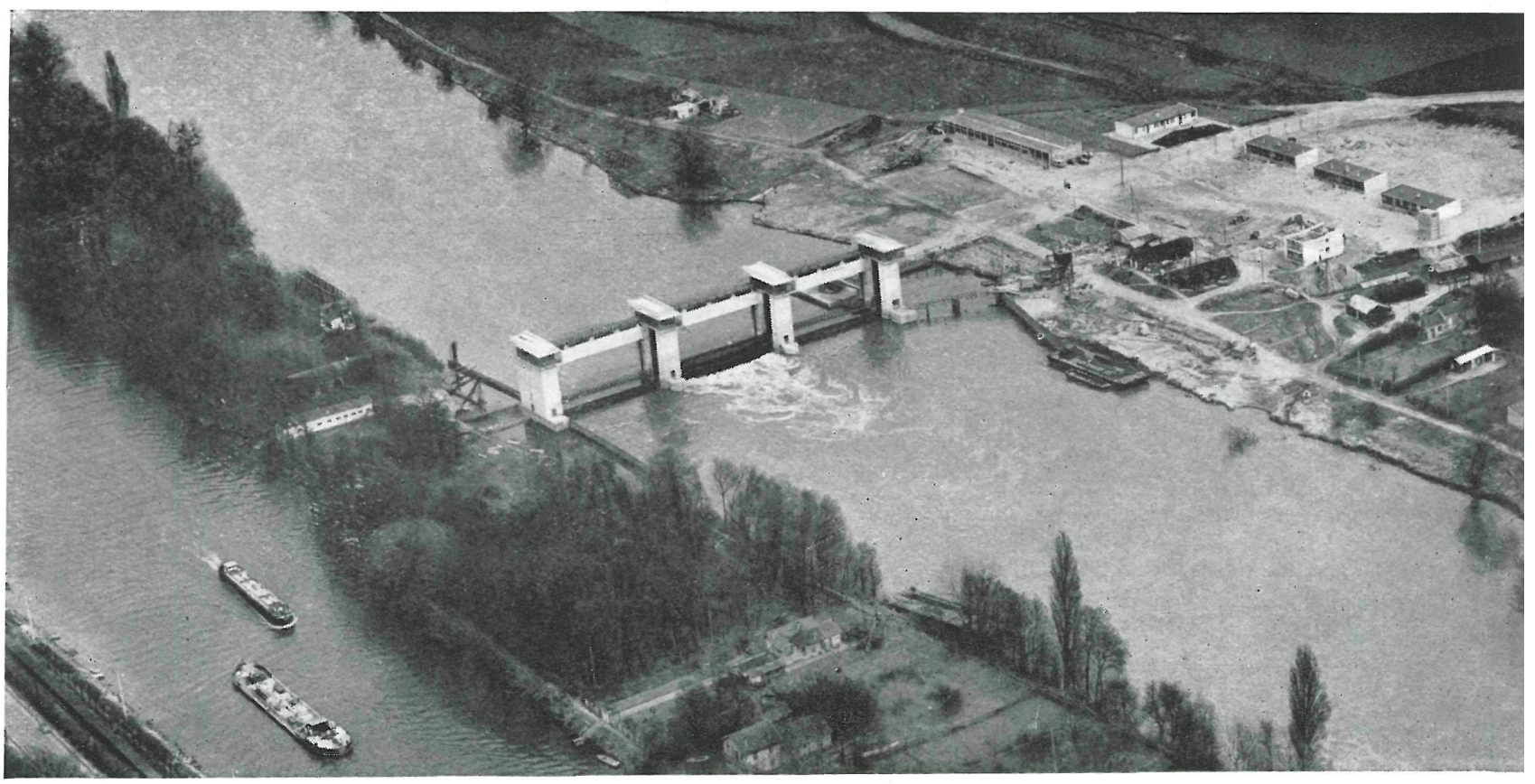




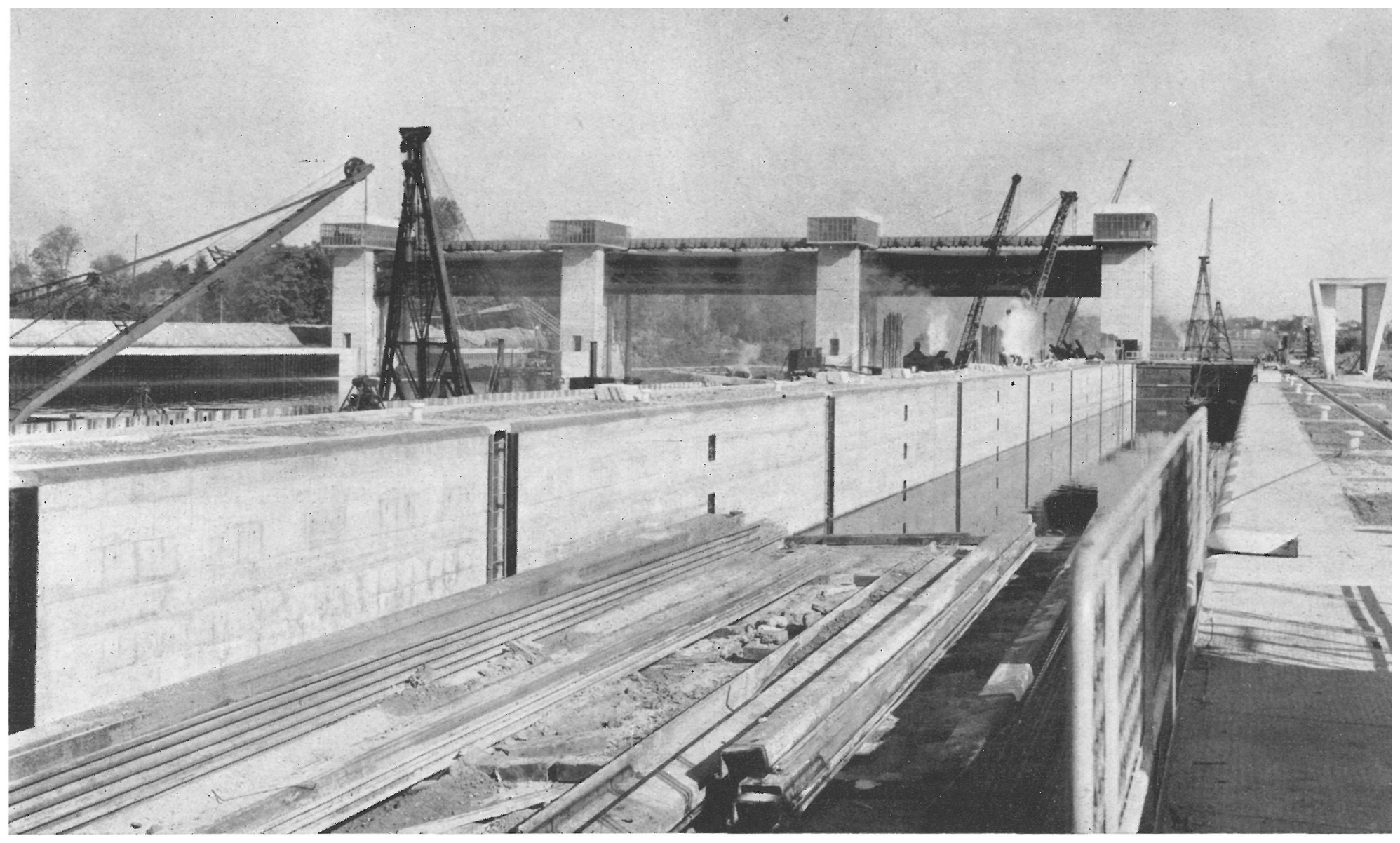

Para asegurar la impermeabilización se hincaron tablestacas metálicas formando dos pantallas, una de aguas arriba y otra en aguas abajo, formando células con otras transversales para evitar una posible subpresión en la solera.

La presa propiamente dicha está constituída por tres pasas o tramos que dan lugar las dos pilas centrales y los estribos. Tanto las pilas como los estribos tienen $20,50 \mathrm{~m}$ de longitud, $5 \mathrm{~m}$ de anchura y $19 \mathrm{~m}$ de altura. La parte superior se ha coronado con las cabinas que contienen la maquinaria para la maniobra de las compuertas que regulan el plano de retención de aguas. Los tajamares son cilíndricos, y ogivales sus partes opuestas de aguas abajo.

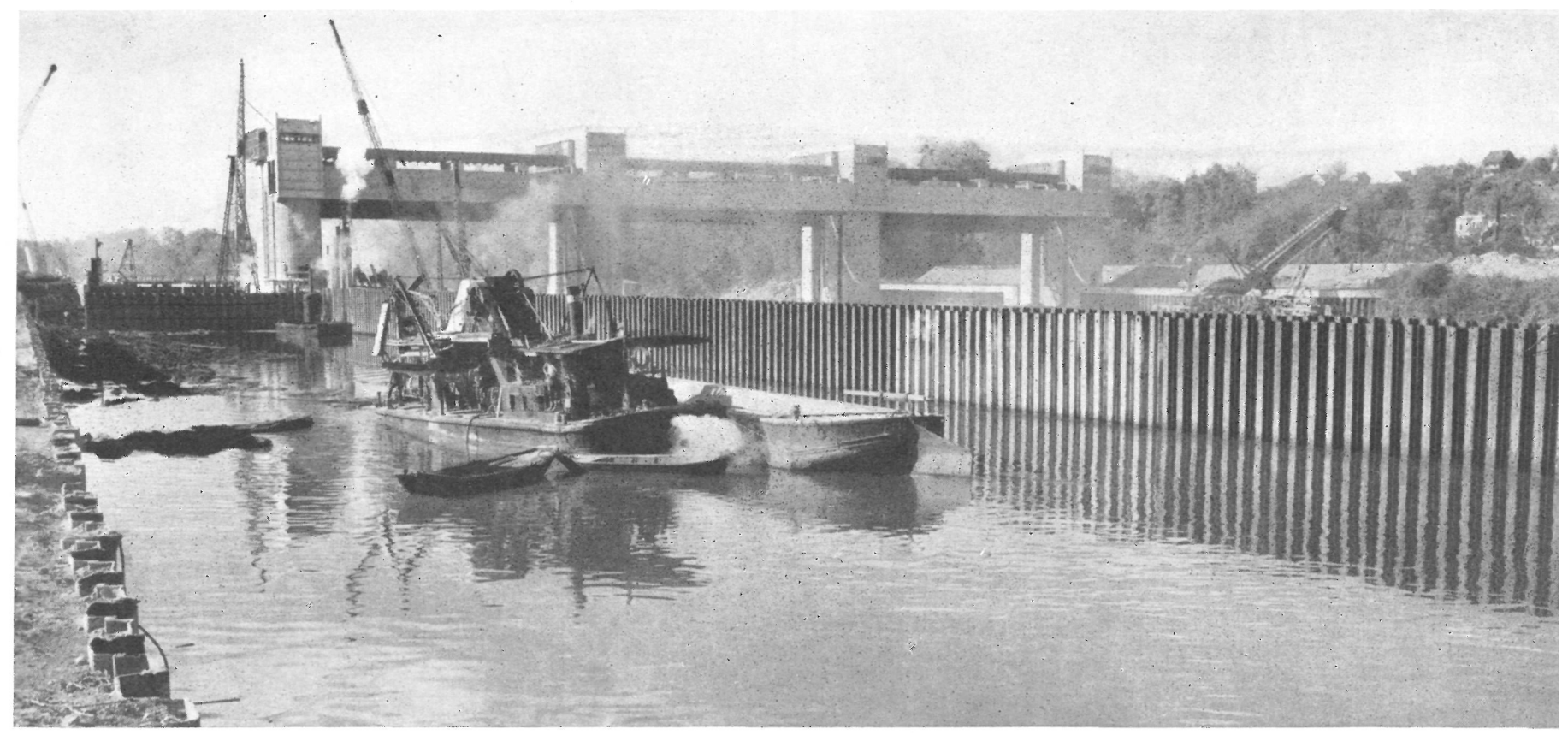




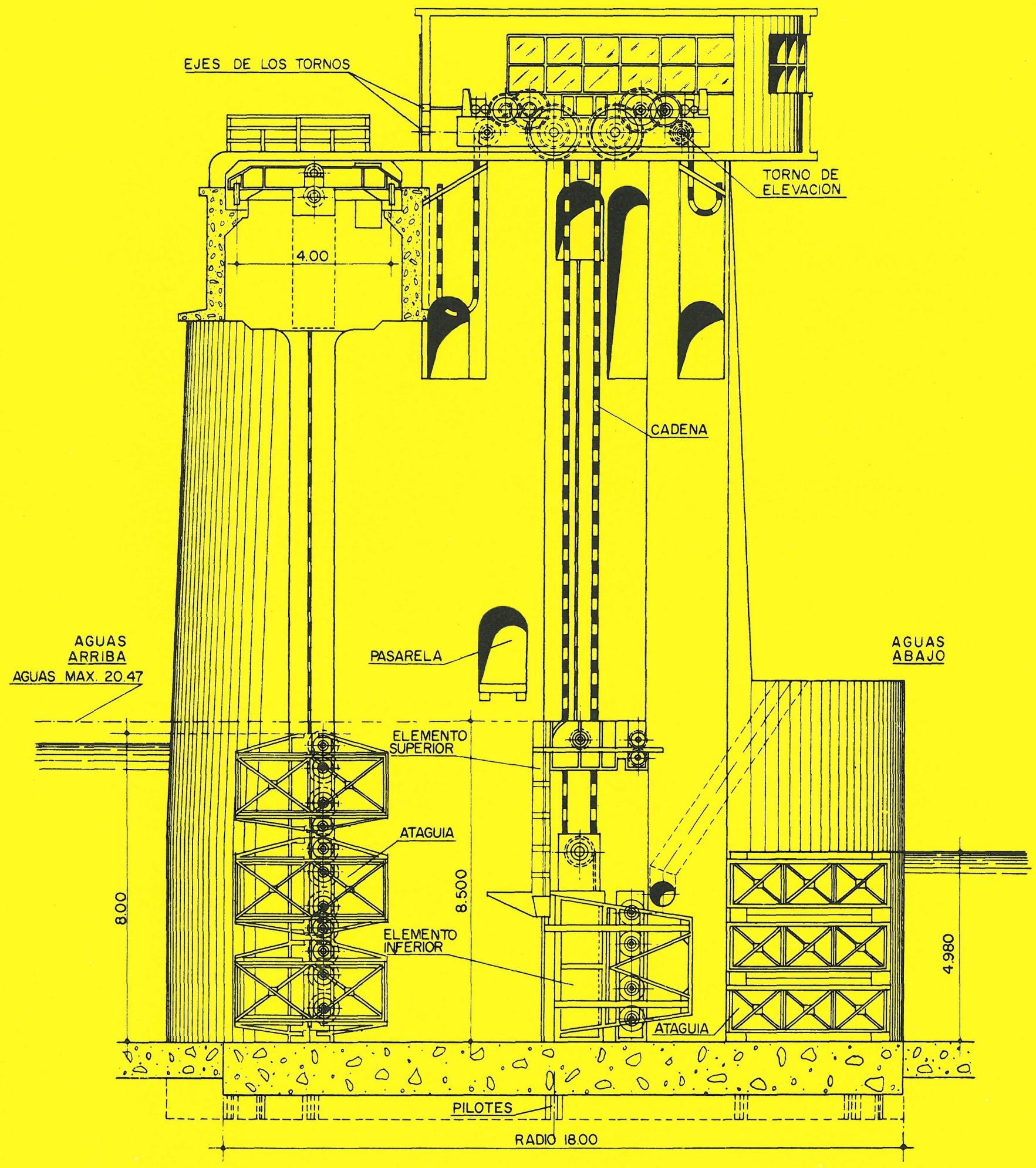

Cada una de las tres compuertas que cierran los tres tramos se compone de dos elementos metálicos, uno inferior y otro superior. El superior es el que regula el nivel de aguas, y tanto uno como otro tienen sus guías encajadas en ranuras que se han dejado en pilas y estribos. El elemento superior de $4 \mathrm{~m}$ de altura, para 112 toneladas, y el inferior de $4,5 \mathrm{~m}$ de altura para 46 toneladas. El elemento superior puede deslizar sobre el inferior $3 \mathrm{~m}$. La carrera de las compuertas es de $17,50 \mathrm{~m}$, que pueden recorrer las compuertas con velocidad de $0,25 \mathrm{~m}$ por minuto, es decir, que cada pasa puede quedar libre de cierres en una media hora. 

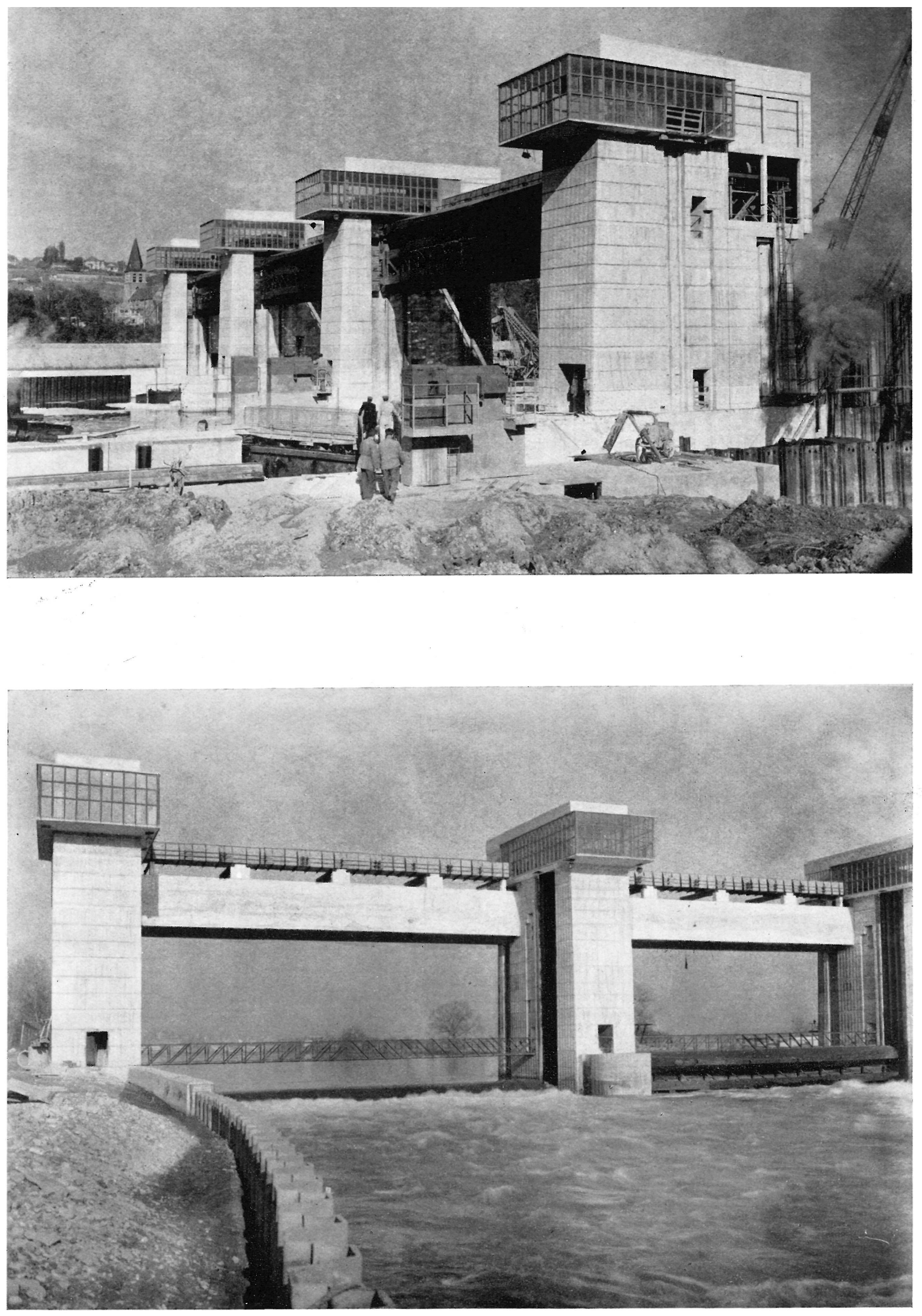


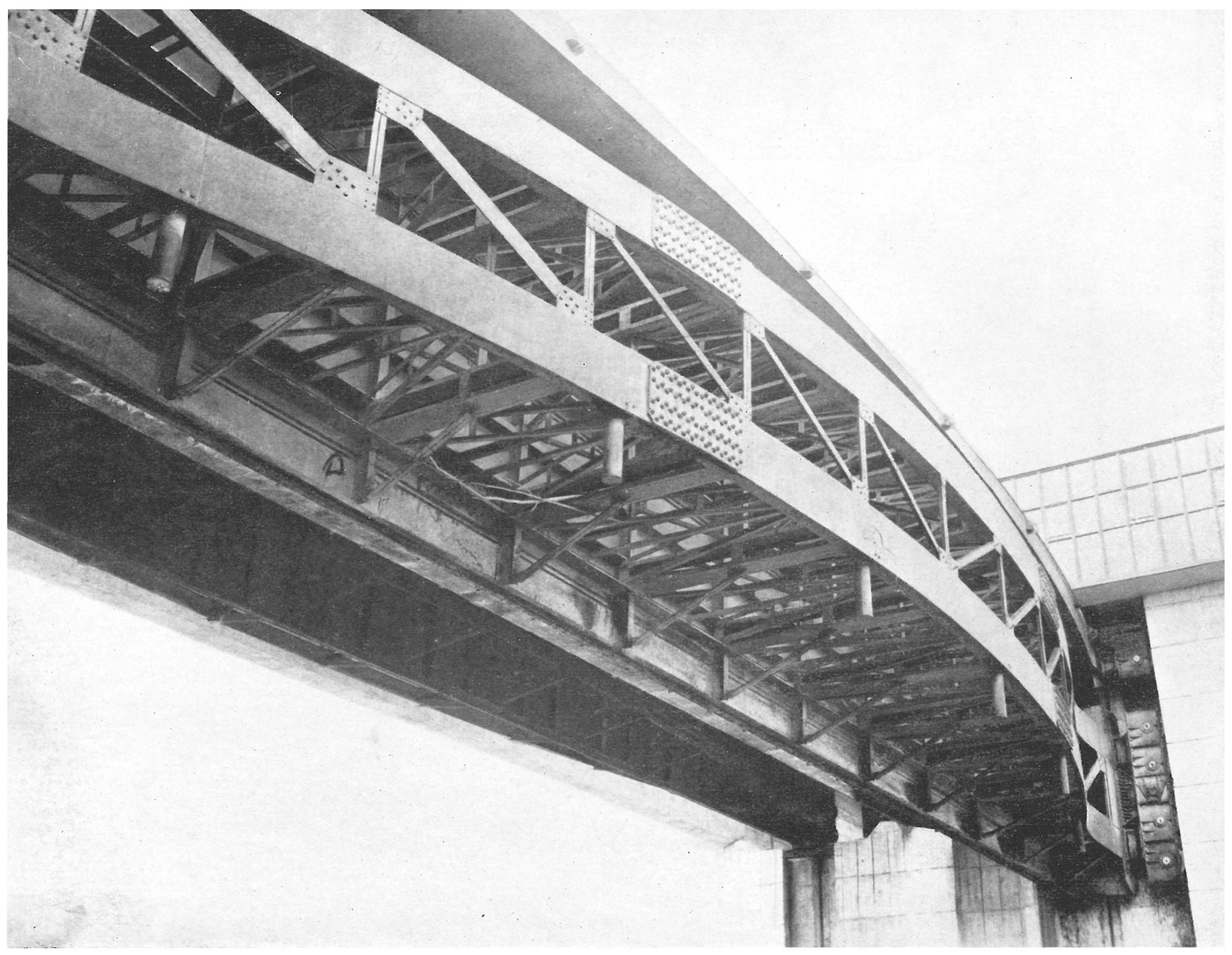

Para la maniobra de estas compuertas se dispone de dos tornos de 95 toneladas de potencia cada uno. Los movimientos de los dos elementos son independientes, pero se pueden regular sus movimientos relativos.

Las ataguías previstas para el cierre de los tres tramos se componen de tres elementos iguales, a los que se les ha dado rigidez por medio de dos vigas parabólicas. El peso de cada elemento es de 53 toneladas.

Para apoyo de las guías del puente-grúa se ha construído una pasarela formada por dos vigas de hormigón armado, independientes, de $3,50 \mathrm{~m}$ de canto, $0,60 \mathrm{~m}$ de anchura y espaciadas a $5,15 \mathrm{~m}$. Para el servicio de la presa se ha construído un puente metálico que puede ser elevado por los tornos de las compuertas si se quiere liberar el tramo de obstáculos.

Al lado de la presa se ha construído una esclusa que viene a aliviar la insuficiencia de otras para la creciente navegación fluvial. Esta esclusa se ha construído teniendo en cuenta que el calado previsto para el futuro en el río Sena sería de $5,10 \mathrm{~m}$. La longitud de la esclusa es de $160 \mathrm{~m}$ y tiene $12 \mathrm{~m}$ de anchura.

La esclusa, construída sobre una capa de arcilla, se apoya en una solera que descansa sobre pilotes de hormigón armado y del mismo tipo de los que se han utilizado en la cimentación de la presa. Los muros laterales, así como la solera son de hormigón armado.

El desnivel que salva la esclusa es de $2,84 \mathrm{~m}$. Para las operaciones de esclusar y vaciar se han construído conductos de $2,5 \times 2 \mathrm{~m}$ cuyas compuertas se accionan eléctricamente.

Por razones económicas, la esclusa, salvo el equipo electromecánico, será anegada durante las crecidas del río, ya que en este caso la navegación por el mismo es libre. La esclusa se llena o se vacía a una velocidad de 0,50 m por minuto. De los cálculos realizados se desprende que las corrientes así producidas crean esfuerzos del orden de 1/600 del tonelaje de la embarcación, esfuerzo que ha servido de base para el cálculo de bolardos. 